\title{
A linear B-cell epitope on the class 3 outer- membrane protein of Neisseria meningitidis recognized after vaccination with the Norwegian group B outer-membrane vesicle vaccine
}

\author{
Alexei A. Delvig, ${ }^{1}$ Elisabeth Wedege, ${ }^{1}$ Dominique A. Caugant, ${ }^{2}$ \\ Rolf Dalseg, ${ }^{1}$ Jan Kolberg, ${ }^{1}$ Mark Achtman ${ }^{3}$ and Einar Rosenqvist ${ }^{1}$
}

Author for correspondence: Alexei A. Delvig. Tel: +47220426 48. Fax: +4722042301.

1,2 National Institute of Public Health, Departments of Vaccines ${ }^{1}$ and Bacteriology2, N-0462 Oslo, Norway

3 Max Planck Institut für molekulare Genetik, Ihnestraße 73, D-14195 Berlin, Germany

\begin{abstract}
The class 3 outer-membrane protein (OMP) of Neisseria meningitidis is a potential target for bactericidal and opsonic antibodies in humans. Synthetic peptides spanning the class 3 OMP from the vaccine strain 44/76 (B: 15:P1.7,16:L3,7) were synthesized on pins and screened with serum obtained from Norwegian adolescents immunized with a meningococcal serogroup B outer-membrane vesicle (OMV) vaccine. A strong IgG response to a single peptide ( ${ }^{19}$ FHQNGQVTEVTr ${ }^{30}$ ) located within loop 1 (VR1) was stimulated after three doses of OMV vaccine in three vaccinees selected on the basis of their antibody response to class 3 OMP. No clear linear B-cell epitopes were recognized by four different murine serotype 15-specific mAbs. A 23mer peptide (D63b2) containing loop 1 of the class 3 OMP was synthesized, and the IgG responses were measured in pre- and post-vaccination serum from 27 vaccinees. Specific IgG rose significantly in $37 \%$ of vaccinees 6 weeks after the second dose and in $74 \%$ of the vaccinees 6 weeks after the third dose of the OMV vaccine. Most immune sera reacted distinctly on immunoblots with denatured class 3 OMP, and the immunoblotting reactivity correlated strongly with concentration of the IgG antibodies specific for peptide D63b2. When added to a post-vaccination serum from one vaccinee, peptide D63b2 competed efficiently with the class 3 OMP for specific antibody binding on immunoblots and in pin ELISA. The results show that the significant part of the humoral response to the meningococcal class 3 OMP elicited by vaccination with the Norwegian OMV vaccine was directed against a single continuous epitope.
\end{abstract}

Keywords: Neisseria meningitidis, PorB protein, B-cell epitope, murine mAbs, synthetic peptides

\section{INTRODUCTION}

Neisseria meningitidis serogroup B strains are the primary cause of meningococcal infection in industrialized countries (Vedros, 1987). Elevated levels of serogroup B

\footnotetext{
Abbreviations: BCE, B-cell epitope; HLA, histocompatibility leukocyte antigens; mAb, monoclonal antibody; OMP, outer-membrane protein; OMV, outer-membrane vesicle; TCE, T-cell epitope; TFA, trifluoroacetic acid.

The GenBank/EMBLDDBJ accession number for the sequence reported in this paper is $X 83428$.
}

disease have been registered in Norway since the mid1970 s, and an experimental outer-membrane vesicle (OMV) vaccine was used to immunize 90000 adolescents. The estimated protection rate was $57 \%$ after 30 months of observation time in a double-blinded placebo-controlled protection trial $(25 \mu \mathrm{g}$ per dose of the vaccine administered twice at 6-week intervals) (Bjune et al., 1991b). The vaccine was based on strain $44 / 76$ (B: 15: P1.7,16:L3,7) and contained the PorA protein (class 1 ), the PorB protein (class 3 ), the Opc protein and other components (Fredriksen et al., 1991). Vaccination elicited antibodies to the P1.16 epitope of the PorA 
protein, bactericidal IgG antibodies to the Opc protein (Rosenquist et al., 1993a, b; Wedege et al., 1991) as well as opsonic antibodies that reacted with meningococci which express the class 3 outer-membrane protein (OMP) (Guttormsen et al., 1993a). Details on the epitopes recognized by these various antibodies are lacking and their relevance to protection remains unknown.

Murine monoclonal antibodies ( $\mathrm{mAbs}$ ) to the class 2 and $3 \mathrm{OMP}$ are the basis of the current serotyping scheme for serological subdivision of meningococci into about 20 serotypes (Frasch et al., 1985). These mAbs are directed mainly to conformational epitopes (Zapata et al., 1992) and have some protective activity in the infant rat infection model (Saukkonen $e t$ al., 1987). Either class 2 or 3 major outer-membrane porins are expressed by all meningococcal strains, and they are encoded by two alleles of the por $B$ gene (Hitchcock, 1989). The porB gene has been cloned and DNA sequences have been determined for the majority of serotype proteins (Feavers $e t$ al., 1992; Ward et al., 1992; Wolff \& Stern, 1991; Butcher et al., 1991; Zapata et al., 1992). The class 3 OMP sequence has $80 \%$ homology with that of gonococcal protein IA and $60-70 \%$ homology with that of the class 2 OMP (Butcher et al., 1991; Ward et al., 1992). A molecular model for the PorB structure predicts eight surfaceexposed hydrophilic loops of differing length (van der Ley et al., 1991), with loops 1 and 5 bearing variable regions VR1 and VR2, respectively (Zapata et al., 1992).

We have previously observed that the majority of postvaccination human sera reacted with denatured class 3 protein on immunoblots (Wedege et al., 1991), suggesting that they contain antibodies that recognize linear epitopes on the class 3 OMP. The aim of this study was to identify such linear BCE using synthetic peptides derived from the class 3 OMP. We also studied the kinetics of the IgG responses to these $\mathrm{BCE}$ in human serum. A small immunodominant region located within loop 1 of the class 3 OMP stimulated IgG antibodies in the majority of the vaccinees.

\section{METHODS}

OMV vaccine. Strain 44/76 (B:15: P1.7,16: L3,7) (Holten, 1979) was the ET-5 strain used for production of the serogroup B OMV vaccine. The vaccine consisted of deoxycholate-extracted OMVs absorbed to aluminum hydroxide and contained the class 1-4 proteins, Opc protein, a class 5 protein which reacts with $\mathrm{mAb}$ P5.5, as well as small amounts of less well-characterized membrane proteins, plus about $8 \%$ lipooligosaccharide (Fredriksen et al., 1991).

Human volunteers and serum samples. The following experiments were approved by the Ethical Committee for Medical Sciences in Norway. Twenty seven Norwegian adults were immunized at weeks 0 and 6 , and after 4 years with $25 \mu \mathrm{g}$ OMV meningococcal group $B$ vaccine (produced by the National Institute of Public Health, Norway) (Bjune et al., 1991a). Serum was drawn before immunization, 6 weeks after the first dose, 6 weeks and 4 years after the second dose, 6 weeks and 1 year after the third dose.

Murine mAbs. MN15A14H6 (serotype 15, IgG2a) (Abdillahi \& Poolman, 1987; Abdillahi, 1988) was provided by Dr J. T.
Poolman, 2-2-P15 (serotype 15, IgG2a) (Zollinger et al., 1984) was obtained from Dr W. D. Zollinger. Other serotype 15specific mAbs, 188,C-1 (IgG3) and 152,D-8 (IgG1) (see below), were produced by the National Institute of Public Health, Norway.

Production of murine serotype 15-specific mAbs. Balb/C mice were immunized subcutaneously with $50 \mu \mathrm{g}$ OMV from strain 44/76 emulsified in Freund's complete adjuvant at 0 and 2 weeks. Three days before fusion, mice were boosted intraperitoneally with $50 \mu \mathrm{g}$ OMV diluted in PBS. Fusion of spleen cells with non-secretor murine myeloma cells was performed in the presence of polyethylene glycol 1450 (Kodak) by standard methods. The hybridoma supernatants were screened in ELISA for reactivity against OMV prepared from strain 44/76 as described (Harthug et al., 1986). Positive hybridomas were expanded and culture supernatants were analysed by immunoblotting using OMV in the presence or the absence of $0.25 \%$ Empigen BB (Albright \& Wilson) as described by Wedege et al. (1988). Class 3 OMP-specific hybridomas were cloned by limiting dilution, expanded and used as culture supernatants. Kit no. 93-6550 from Zymed was used for isotyping. The serotype 15 specificity of $152, \mathrm{D}-8$ and $188, \mathrm{C}-1 \mathrm{mAbs}$ was confirmed by whole-cell ELISA as described (Abdillahi \& Poolman, 1987).

DNA sequence analysis. Chromosomal DNA was isolated from strain 44/76 as described (Kapperud et al., 1990), except for an additional $2 \mathrm{~h}$ treatment of the DNA solution with boiled RNase A $\left(20 \mu \mathrm{g} \mathrm{ml}^{-1}\right.$, Sigma) before the second phenol/ chloroform extraction. DNA concentration and purity were determined spectrophotometrically and electrophoretically. The primers (synthesized by the Biotechnology Centre, Oslo) corresponded to the anti-sense strand of the region encoding the seven $C$-terminal amino acids of the class 3 protein plus the TAA stop codon (Maiden et al., 1991) (P-733: 5'-TTA GAA TTT GTG GCG CAA ACC GAC-3') and encoded the first eight amino acids of the signal peptide (P-907: 5'-ATG AAA AAA TCC CTG ATT GCC CTG AC-3').

The PCRs were performed as described (Wedege et al., 1993) except that the annealing temperature was $60^{\circ} \mathrm{C}$. PCR products were separated from the primers by centrifugation through a Chroma Spin + TE 100 column (Clontech). Sequencing primers (the two primers used in the PCR reaction plus the primers P1472, 5' -TCC GTA CGC TAC GA(TC) TCT CCC G-3', and P1473, 5'-CCG GCG TGG TAA GA-3') were labelled with $\left[{ }^{33} \mathrm{P}\right] \mathrm{ATP}$, and the amplified material was sequenced by the Taq DNA sequencing kit (Perkin Elmer Cetus), followed by addition of formamide stop buffer. Products of the sequencing reactions were analysed with $6 \%(\mathrm{w} / \mathrm{v})$ polyacrylamide sequencing gels and autoradiographed as described by Wedege et al. (1993).

Immunoblotting. Boiled OMV from strain 44/76 was used as antigen. After electrotransfer, blots were incubated with human sera (diluted $1: 200$ ) in the presence or the absence of $0.15 \%$ Empigen BB to enhance renaturation of the antigens (Wedege $e t$ al., 1988). The intensity of the IgG antibody binding to the class 3 OMP was scored visually from 0 (no binding) to 4 (strong binding).

\section{Synthetic peptides}

(i) Solid phase peptide synthesis. The deduced amino acid sequence of the serotype 15 protein was used to manually synthesize multiple synthetic N-terminally acetylated $12 \mathrm{mer}$ peptides on pins which spanned the entire class 3 molecule with overlaps of 6 amino acids. Peptide synthesis was performed in duplicate using a commercially available Epitope scanning Kit 
V2.0 (Cambridge Research Biochemicals) according to the manufacturer's instructions.

Other synthetic peptides (Table 1) were synthesized at $0.25 \mathrm{mmol}$ scale using FastMoc technology with an automated peptide synthesizer (model $431 \mathrm{~A}$, Applied Biosystems) in one synthesis run. The peptides were synthesized using Rink resin (TentaGel S RAM, Rapp Polymere), which results in a Cterminal amide cap, and peptide D63a2 was acetylated at the $\mathrm{N}$ terminus with acetic anhydride. Activation and coupling was done in the presence of 2-(1 H-benzotriazol-1-yl)-1,1,3,3,tetramethyluronium hexafluoro-phosphate/diisopropylethylamine according to the manufacturer's instructions (FastMoc). Synthesis used Fmoc protected amino acids with trityl-(Gln, Asn), $t$-butyl-(Ser, Thr) or $t$-butyloxycarbonyl-(Lys) side-chain protection. The efficiency of the Fmoc de-protection of the growing peptide chain was monitored by following formation of a piperidine adduct at $301 \mathrm{~nm}$.

Side-chain deprotection and cleavage from the resin support (6 $\mathrm{h}$ at room temperature) was achieved with $2.5 \%(\mathrm{v} / \mathrm{v}) 1,2-$ ethanedithiol, $2.5 \%$ water and $95 \%$ trifluoroacetic acid (TFA) (peptides D63a1 and D63a2) or with 7.5\% (v/v) crystalline phenol, $2.5 \%$ 1,2-ethanedithiol, $5 \%$ thioanisole, $5 \%$ water, $80 \%$ TFA (peptide D63b2).

Peptides were recovered by precipitation with $t$-butyl methyl ether (Merck) followed by centrifugation. After lyophilization, peptides D63a1, D63a2 and D63b2 were dissolved in TFA, precipitated by dilution in 20 vols $1 \%$ acetic acid, $10 \%$ methanol, centrifuged, then redissolved in $50 \%$ methanol and lyophilized. This material was then dissolved in $1 \%$ acetic acid (D63a1), 5\% acetic acid, 5\% acetonitrile (D63a2), 1\% acetic acid, 3\% acetonitrile (D63b2) (Table 1), and purified by reversed phase-HPLC chromatography (Pep-S, C2/C18, $100 \AA$ pore size, $12 \mu \mathrm{m} \times 22.5 \mathrm{~mm} \times 25 \mathrm{~cm}$, Pharmacia) using a gradient of acetonitrile, $0 \cdot 1 \%$ TFA. Lyophilized peptides were stored at $20^{\circ} \mathrm{C}$.

(ii) Epitope mapping. The pins containing synthetic peptides were screened by ELISA for reactivity with human serum (diluted 1:500) or murine mAbs (152,D-8 and 188,C-1 mAbs were used as culture supernatants diluted 1:5; ascites fluids MN15A14H6 and 2-2-P15 were diluted 1:8000 and 1:5000, respectively). After incubation for $18 \mathrm{~h}$ at $4{ }^{\circ} \mathrm{C}$, the pins were incubated with horseradish peroxidase conjugated rabbit antimouse Ig (1:1000) or rabbit anti-human Ig ( $\gamma$-chains) (1:500) (Dakopatts) for $90 \mathrm{~min}$ as described (Virji \& Heckels, 1989). Incubation of the pins with these conjugates alone resulted in no significant colour development. Each antibody sample was tested independently with duplicate sets of the pins.

(iii) Synthetic peptide ELISA. The optimal concentration of peptide D63b2 $\left(5 \mu \mathrm{g} \mathrm{ml}^{-1}\right)$ and anti-human IgG $\left(3 \mu \mathrm{g} \mathrm{m}^{-1}\right)$ was determined by checkerboard titration. To quantify the peptidespecific IgG concentration in human sera, peptide D63b2 was coated on six rows of microtitre plates (MaxiSorp NuncImmuno plate F96, Nunc) in $0.05 \mathrm{M}$ carbonate buffer, $\mathrm{pH} 9.6$ at $35^{\circ} \mathrm{C}$ until dry (at least $16 \mathrm{~h}$ ). A calibration ELISA was set up using the remaining two rows of the plate which were coated with goat anti-human IgG ( $\gamma$-chain specific) in $0.05 \mathrm{M}$ carbonate buffer, $\mathrm{pH} 9.6$ at $4{ }^{\circ} \mathrm{C}$ for $16 \mathrm{~h}$. The plates were blocked (blocking buffer: PBS containing 2\%(w/v) BSA and 0.05\% Tween 20) for $90 \mathrm{~min}$ at room temperature. Tests with human serum (diluted 1:50 in blocking buffer) were performed in duplicate against both D63b2 peptide and uncoated plastic. Simultaneously, a dilution series of purified human IgG (Dako) was applied in the rows coated with goat anti-human IgG. After $90 \mathrm{~min}$ incubation at room temperature and washing, alkaline phosphatase conjugate (diluted 1:500) of swine anti-human IgG $(\gamma$-chain specific) (Orion Diagnostica) was reacted for an additional $90 \mathrm{~min}$. After washing in PBS containing $0.05 \%$ Tween 20 , reactions were developed with $p$-nitrophenyl phosphate $\left(1 \mathrm{mg} \mathrm{ml}{ }^{-1}\right.$ in diethanolamine buffer $)$ for $60 \mathrm{~min}$ at $36^{\circ} \mathrm{C}$, and read at $405 \mathrm{~nm}$. Since the slopes of titration curves obtained in the peptide ELISA and in the anti-human IgG ELISA were similar, the concentration of $\operatorname{IgG}$ antibodies against peptide D63b2 was calculated according to the four parameters loglogistic model for single analytes (Plikaytis et al., 1991) using the $A_{405}$ data with the dilution series of the purified human IgG as a standard. Pearson product-moment correlations were computed between the peptide-specific IgG and immunoblotting scores (significance level $P \leqslant 0 \cdot 05$ ).

(iv) Competition experiments. Reactivity with pins, on immunoblots and in the peptide ELISA were compared for the post-vaccination serum obtained 6 weeks after the third dose from vaccinee no. 1085 in the absence and the presence $(20 \mu \mathrm{g}$ per $40 \mu \mathrm{l}$ serum) of peptide D63b2.

\section{RESULTS}

\section{Analyses of linear epitopes recognized by human serum}

The deduced amino acid sequence of the serotype 15 protein from strain $44 / 76$ was used for synthesizing peptides on pins with maximal conservation of the linear structure of the variable regions (12mers overlapping by six amino acids).

Epitope mapping was done by selecting three vaccinees out of 27 volunteers (1061, 1467 and 1085) whose serum, taken after the third vaccine dose, contained IgG antibodies which showed strong binding to the class 3 OMP on immunoblots in the absence of detergent (Fig. 1, tracks 2, 4 and 6). These post-vaccination sera bound with

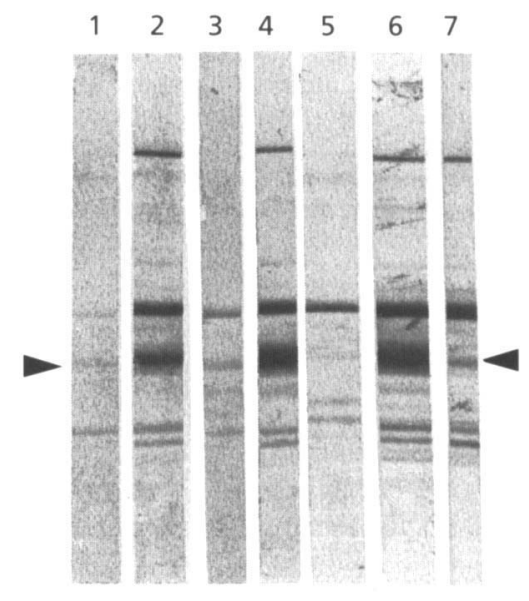

Fig. 1. Reactivity of human pre- and post-vaccination sera on immunoblots in the absence of detergent against the OMV preparation from strain 44/76. Tracks: 1 (pre-vaccination sera from vaccinee 1061 ); 2 (1061 post-); 3 (1467 pre-); 4 (1467 post-); 5 (1085 pre-); 6 (1085 post-); 7 (1085 post- in the presence of peptide D63b2; competition experiment). Arrowheads denote the position of the class 3 protein. 

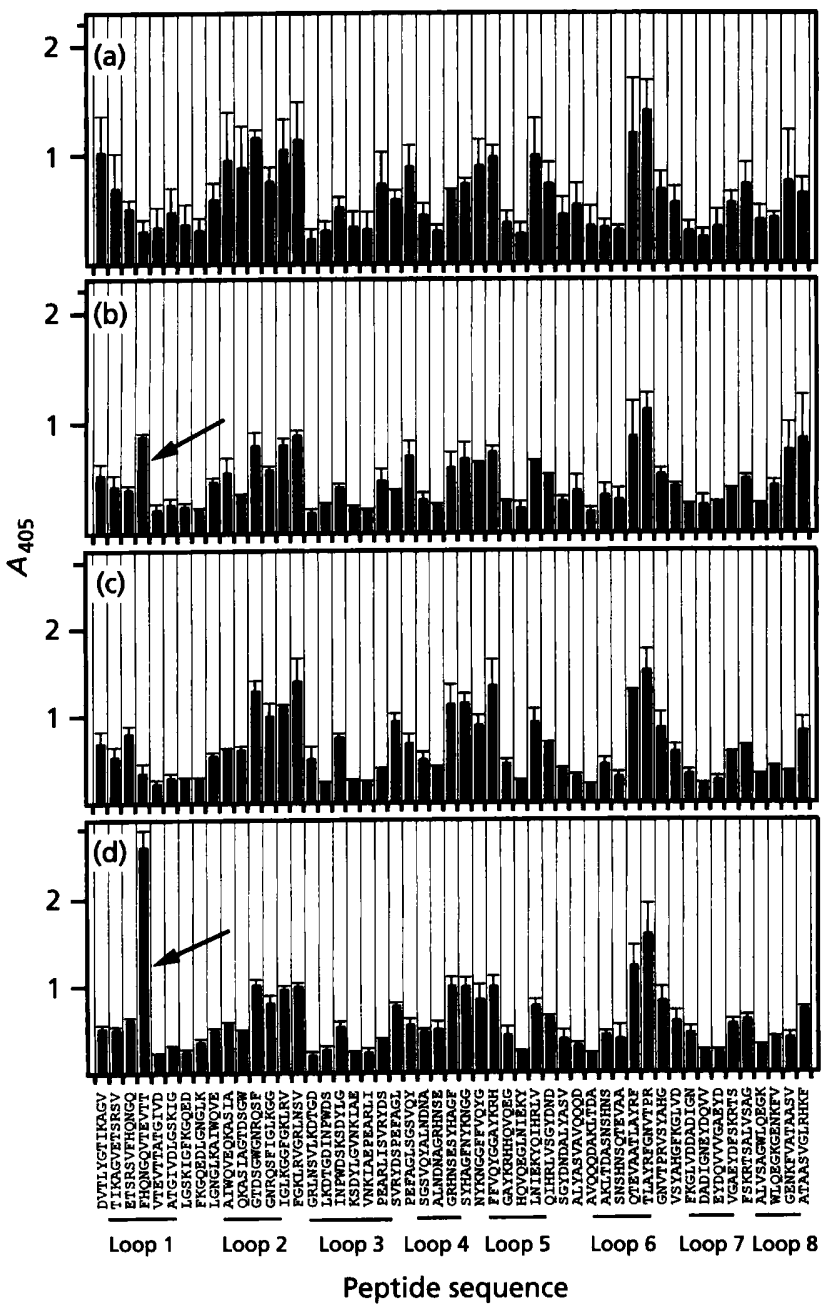

Fig. 2. ELISA reactivity of paired pre- and post-vaccination sera from two vaccinees with synthetic peptides on pins. Prevaccination serum from vaccinees 1061 and 1467 is shown in panels (a) and (c), respectively, and the corresponding postvaccination serum, obtained after the third dose, is shown in panels (b) and (d). Synthetic peptides corresponding to the putative surface-exposed regions named loops 1 through 8 (Zapata et al., 1992) are underlined. Arrows point to the peptide recognized by post-vaccination sera ( ${ }^{19} \mathrm{FHQNGQVTEVTT}{ }^{30}$, peptide number 4). Results summarize two separate experiments on two different sets of pins. The bars represent the mean, and the error bars show SD of the mean.

different intensities to the class $3 \mathrm{OMP}$, in accordance with the quantitative reactivity of those sera with synthetic peptide D63b2 (see below). Binding was negligible in the pre-vaccination serum from these volunteers.

Pre- and post-vaccination serum from those three vaccinees were tested with the pins containing the synthetic 12 mers peptides. The post-vaccination sera from all three vaccinees showed a significant increase in binding, relative to the pre-immune sera, with one $12 \mathrm{mer}$ peptide $\left({ }^{19} \mathrm{FHQNGQVTEVTT}{ }^{30}\right.$, peptide number 4$)$ from the VR1 (loop 1) region (Figs 2 and 3). Strong binding to other peptides located on loops 2 and 4

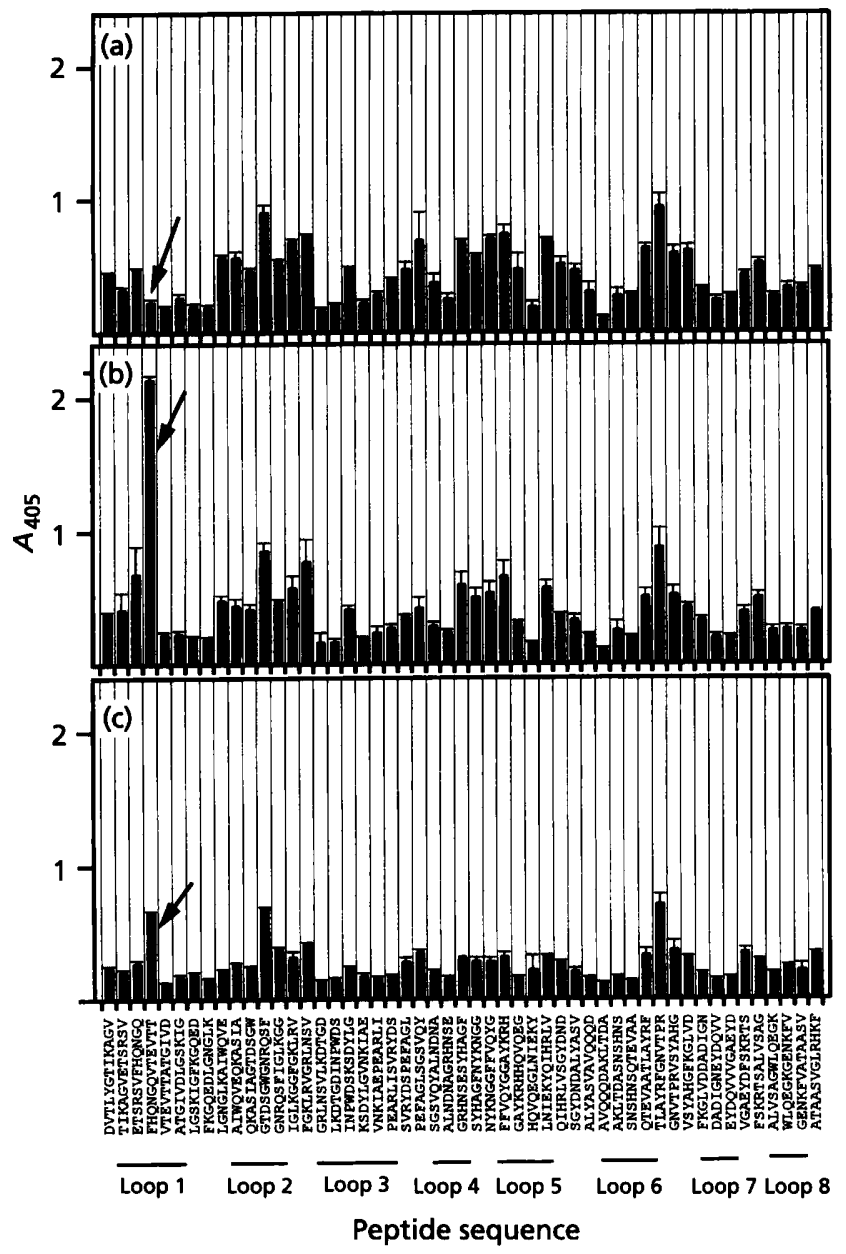

Fig. 3. ELISA reactivity of (a) pre- and (b) post-vaccination sera from vaccinee 1085 with synthetic peptides on pins. (c) Postvaccination serum in the presence of peptide $\mathrm{D} 63 \mathrm{~b} 2$ (competition experiment). Other details as in the legend to Fig. 2

(peptides 12 and 26, respectively) and on the transmembrane regions following loops 2,4 and 6 (peptides 14-15, 27-28 and 40, respectively), was comparable between the paired pre- and post-vaccination sera studied.

\section{Mapping of the serotype 15 epitopes by murine mAbs}

To locate regions important for serotype specificity, four murine serotype 15 -specific $\mathrm{mAbs}$ were tested with the pin-bound 12 mer peptides. Those $\mathrm{mAbs}$ bound to numerous unrelated peptides and showed no clear pattern of reactivity with a single epitope (Fig. 4). The strongest reaction for $\mathrm{mAb} 152, \mathrm{D}-8$ was with the peptide ${ }^{19}$ FHQNGQVTEVTT ${ }^{30}$ (peptide number 4; also recognized by the post-vaccination human sera). Other $\mathrm{mAbs}$ (MN15A14H6, 2-2-P15 and 188,C-1) reacted with various peptides located within loops 2 and 4 or in the trans- 


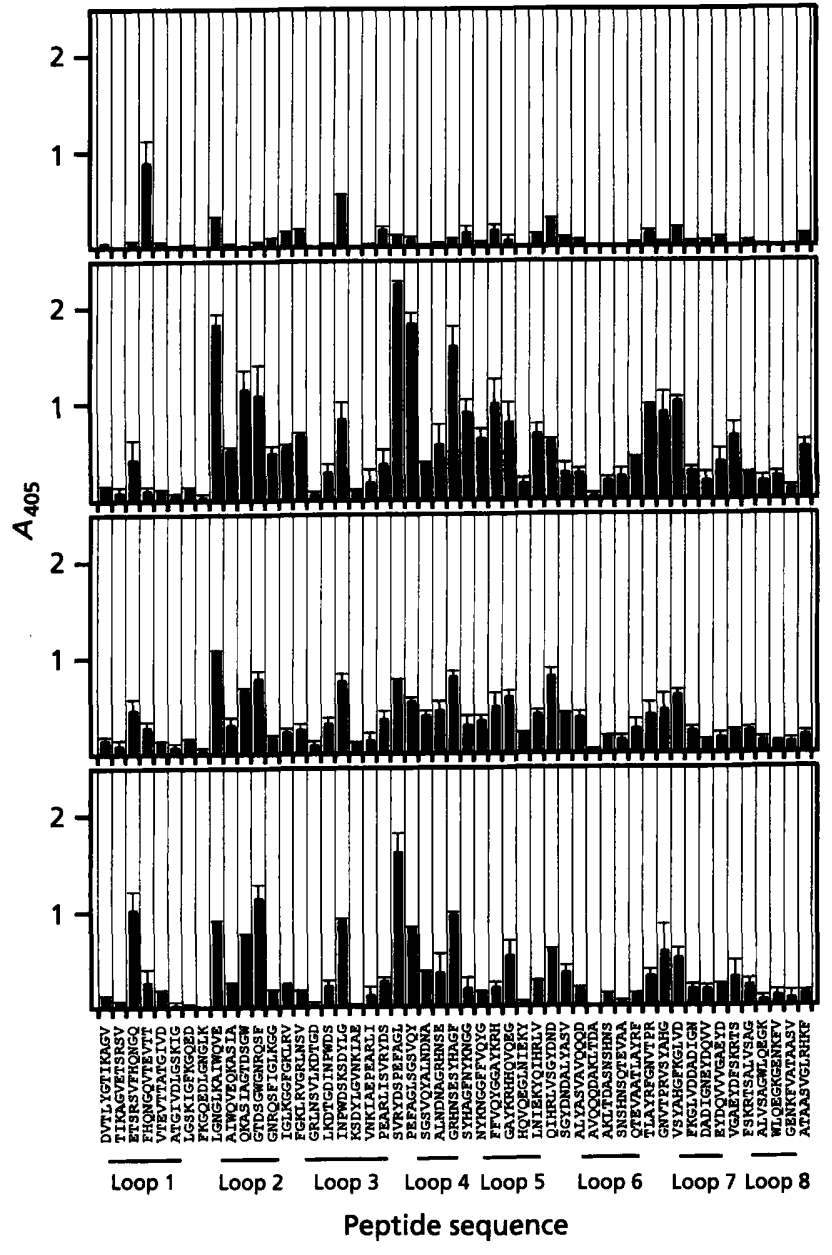

Fig. 4. ELISA reactivity of murine mAbs specific for serotype 15 protein with synthetic peptides on pins. mAbs: (a) 152,D-8; (b) MN15A14H6; (c) 2-2-P15; (d) 188,C-1. Other details as in the legend to Fig. 2.

membrane regions after loops 3 and 6 (also recognized by the pre- and post-vaccination human sera). All mAbs bound to the class 3 protein on immunoblots only in the presence of detergent (data not shown), suggesting that murine serotype 15-specific mAbs recognize discontinuous epitopes (Zapata et al., 1992).

\section{Kinetics of the human IgG response}

Peptides spanning different portions of loop 1 of the serotype 15 protein were synthesized and tested with human serum (Table 1). Since a 16 mer peptide with capped $\mathrm{N}$ - and C-termini (D63a2) was recognized with about 10 -fold lower efficiency (data not shown), compared to a 23 mer peptide (D63b2) mimicking the entire loop 1 of the PorB protein, the latter was used to quantify IgG antibodies reacting with the linear epitope ${ }^{19}$ FHQNGQVTEVTT ${ }^{30}$ in pre- and post-vaccination serum. Serum from vaccinees 1061, 1467 and 1085 obtained 6 weeks after the third dose contained 1.7, 5.9 and $8.2 \mu \mathrm{g} \mathrm{IgG} \mathrm{ml}{ }^{-1}$, respectively, in quantitative agreement with the reactivity against the pin-bound epitope and with the intensity of reactivity with the class 3 OMP on immunoblots (Fig. 1, tracks 2, 4 and 6).

Additional sera (total of 161 sera from 27 participants of the vaccine trial) were also quantitated in peptide ELISA with D63b2 (Fig. 5). None of the vaccinees responded to the D63b2 peptide after the first vaccine dose. Six weeks after the second dose, significant rises (range $0 \cdot 2-2 \cdot 0 \mu \mathrm{g} \mathrm{ml}^{-1}$ ) were observed in $10 / 27(37 \%)$ of the vaccinees. Still stronger reactions were observed in sera taken 6 weeks after the third dose, when $13 / 27$ of the vaccinees showed strong responses (range 1.0-8.8 $\mu \mathrm{g}$ $\mathrm{ml}^{-1}$ ) and $7 / 27$ weaker responses (range 0.3-0.9 $\mu \mathrm{g} \mathrm{ml}^{-1}$ ) in reactive $\mathrm{IgG}$ antibodies. All vaccinees exhibited a strong drop in IgG reacting with peptide D63b2 over the next 12 months, although the mean IgG concentration still remained approximately twofold higher than after the second dose (Fig. 5).

For the 20 vaccinees with detectable antibodies, a significant correlation $(r=0.82, p<0.05)$ was found between the IgG specific for peptide D63b2 and the intensity of IgG binding to the class 3 OMP on immunoblots in the absence of detergent. Serum from one exceptional vaccinee (1510) bound to the class 3 OMP on immunoblots only in the presence of detergent (data not

Table 1. Synthetic peptides mimicking different portions of loop 1 of the serotype 15 protein

\begin{tabular}{|c|c|c|c|}
\hline $\begin{array}{l}\text { D } \\
\text { number }\end{array}$ & Peptide & Sequence & $\begin{array}{c}\text { Reactivity } \\
\text { with } \\
\text { human } \\
\text { serum }\end{array}$ \\
\hline D63a1 & 16 mer & ${ }^{19}$ FHQNGQVTEVTTATGI ${ }^{34}-\mathrm{Am}^{*}$ & - \\
\hline D63a2 & $16 \mathrm{mer}$ & $\dagger \mathrm{N}-\mathrm{ac}-{ }^{19} \mathrm{FHQNGQVTEVTTATGI}{ }^{34}-\mathrm{Am}^{\star}$ & + \\
\hline D63b2 & 23 mer & ${ }^{12}$ VETSRSVFHQNGQVTEVTTATGI ${ }^{34}-\mathrm{Am}^{*}$ & +++ \\
\hline
\end{tabular}

* The C-terminus of each synthetic peptide was protected by an amide group (Am).

† The $\mathrm{N}$-terminus of peptide D63a2 was protected by acetyl group ( $\mathrm{N}$-ac). 


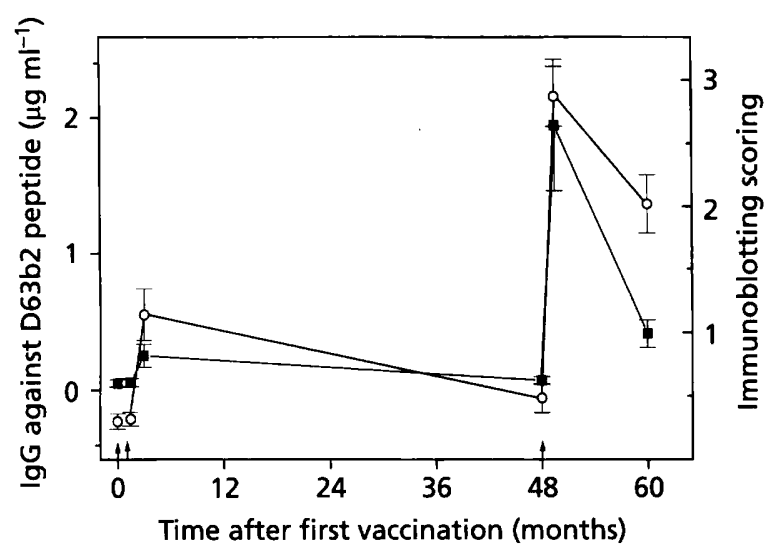

Fig. 5. Kinetics of synthesis following vaccination of IgG antibodies reacting with peptide $\mathrm{D} 63 \mathrm{~b} 2$ and with the class 3 OMP. $\square$, Concentration of IgG measured in ELISA with peptide D63b2; $O$, immunoblotting scoring on an arbitrary scale from 0 to 3 . Arrows indicate individual vaccinations at weeks 0,6 and after 4 years. Data are the mean values for 27 vaccinees and the error bars indicate the standard error of the means.

shown) and showed inefficient binding $\left(0 \cdot 4 \mu \mathrm{g} \mathrm{ml}^{-1}\right)$ to peptide $\mathrm{D} 63 \mathrm{~b} 2$. Serum from six of the seven vaccinees with no detectable IgG antibodies to peptide D63b2 did react with the class 3 OMP band on immunoblots, suggesting that that protein does contain additional epitopes not identified here.

No reaction was detected with the 16 mer peptide D63a1, which differs from D63a2 in having a charged N-terminus, suggesting that charged amino acids near the human BCE hamper interactions with reactive antibodies (Delvig et al., 1994).

\section{Competition experiments}

The 23mer peptide D63b2 was tested for competitive binding using the post-vaccination serum from a vaccinee with a high level of $\operatorname{IgG}$ antibodies to that peptide (1085, $\left.8.2 \mu \mathrm{g} \mathrm{ml}^{-1}\right)$. The presence of $20 \mu \mathrm{g}$ peptide D63b2 in $40 \mu \mathrm{l}$ serum resulted in a distinct reduction in the intensity of binding to the class 3 band on immunoblots (Fig. 1, track 7). We also observed a strong reduction (about $80 \%$ ) in the IgG-reactive with D63b2-coated on ELISA plates as well as in the reaction with the 12 mer peptide ${ }^{19}$ FHQNGQVTEVTT ${ }^{\mathbf{3 0}}$ on pins (Fig. 3c). These data suggest that the BCE located on loop 1 of the class 3 OMP is the immunodominant linear epitope.

\section{DISCUSSION}

Several authors have reported immunodominant B-cell epitopes recognized by murine $\mathrm{mAbs}$ on different proteins expressed by $N$. meningitidis (McGuinness et al., 1993, 1990 ; Morelli et al., 1994; Hobbs et al., 1994; Abdillahi \& Poolman, 1987; Abdillahi, 1988; Zollinger et al., 1984; Thompson et al., 1993; Tinsley et al., 1992; Virji et al.,
1989). T-cell epitopes recognized by human peripheral blood mononuclear cells have also been described (Wiertz et al., 1992), but data on human BCE in meningococcal proteins are more limited (Delvig et al., 1994; Morelli et al., 1994; de Cossio et al., 1992), partially due to the discontinuous nature of many epitopes recognized by human antibodies (Laver et al., 1990).

Using pin-bound 12 mer synthetic peptides overlapping by 6 amino acids, we identified an immunodominant continuous epitope ( $\left.{ }^{19} \mathrm{FHQNGQVTEVTT}{ }^{\mathbf{3 0}}\right)$ located on loop 1 of the serotype 15 protein which was recognized after vaccination with the Norwegian OMV vaccine. Recently, the total antibody responses against the PorB protein have been quantified using purified class 3 protein in serum from patients with meningococcal disease (Guttormsen et al., 1993b). Apart from a significant increase in specific IgG antibodies in $22 / 25$ of those patients, the study also showed considerable heterogeneity in IgG concentrations and subclasses as well as in the kinetics of the IgG responses. We used a $23 \mathrm{mer}$ synthetic peptide (D63b2) covering loop 1 of the serotype 15 protein to quantify the $\operatorname{IgG}$ responses in 161 pre- and post-vaccination sera from 27 vaccinees, and also observed a similar heterogeneity of the $\operatorname{IgG}$ responses to this region. A significant IgG response to the $\mathrm{D} 63 \mathrm{~b} 2$ peptide was determined in $37 \%$ of vaccinees after the second vaccine dose, but a consistent immune response was first found in $74 \%$ of vaccinees after the third dose. The mechanism of this effect is not understood, but may involve inefficient processing and/or presentation of immunogenic peptides, derived from the class 3 OMP, by antigen-presenting cells.

The following observations demonstrate that the overall immune response against the serotype 15 protein, elicited by vaccination, is directed against both linear and conformational epitopes. The pre- and post-vaccination sera bound to other 12 mer peptides (covering loops 2 and 4 , and the trans-membrane regions following loops 2, 4 and 6) (Figs 2 and 3), also recognized by at least three different murine serotype 15 -specific mAbs (MN15A14H6, 2-2-P15 and 188,C-1) (Fig. 4), thus indicating other parts of the PorB protein involved in the putative discontinuous epitope. In addition, seven vaccinees failed to develop any detectable response to the D63b2 peptide after three immunizations, although six of those responded against the class 3 OMP on immunoblots in the presence of detergent, probably recognizing conformational epitopes which would not be detected by pin ELISA tests. Taken together, these observations suggested that, in addition to the linear BCE, undefined discontinuous epitopes on the class 3 OMP are involved in the human immune response to the OMV vaccine.

Recent advances in peptide synthesis make the B-cell epitope described here potentially useful in the development of a synthetic meningococcal vaccine. To this end, synthetic peptides covering the BCE may be used as cyclic peptides or in combination with $\mathrm{T}$-cell epitopes as a multiple antigen peptides (MAP) system, which were shown to stimulate production of bactericidal antibodies 
in mice (Christodoulides et al., 1993; Christodoulides \& Heckels, 1994). Alternatively, different synthetic peptides encompassing the potentially protective meningococal B-cell epitopes and T-cell epitopes can be combined within one construct using template-assembled synthetic proteins design (Mutter \& Vuilleumier, 1989).

To generate antibody responses to protein antigens, immunogenic peptides, released in endocytic vesicles during the processing of a given protein, must associate with the highly polymorphic HLA class II glycoproteins. The specificity of this interaction is determined by polymorphic amino acid residues located in the peptidebinding groove of the HLA class II molecule (reviewed by Vignali \& Strominger, 1994, and by Chicz \& Urban, 1994). Consequently, the observed heterogeneity in immune responses to the 23 mer D63b2 might reflect the HLA class II restriction. Indeed, analysis of the putative HLA class II structural motifs (Chicz et al., 1992; Matsushita et al., 1994) enabled us to recognize an HLADR1 binding motif $\left({ }^{16} \mathrm{R}----\mathrm{Q}---\mathrm{V}^{25}\right)$ which partially overlaps with the human $\mathrm{BCE}$ on the class $3 \mathrm{OMP}$, consisting of 10 amino acids of which the first is positively charged, the sixth is a hydrogen-bond donor and the tenth is hydrophobic. The frequency of HLA-DR1 in the Norwegian population is about $0 \cdot 09$ (Spurkland et al., 1992), and it is unlikely that this motif alone could account for the high frequency of responses to peptide D63b2. No DR4-binding motifs (DRB1*0405 or DRB1*0406) were found.

The results indicate that the Norwegian serogroup B meningococcal OMV vaccine is efficient in stimulating production of antibodies specific for a human linear BCE located within loop 1 of the serotype 15 protein. The relevance of such antibodies for protection is currently under study.

\section{ACKNOWLEDGEMENTS}

We are grateful to T. E. Michaelsen, E. A Høiby, F. Oftung and E. R. van der Voort for discussions and for critically reading the manuscript. We also wish to thank Karin Bolstad for technical assistance. This research project received financial support from the WHO Global Programme for Vaccines (GPV): GPV/V23/181/52.

\section{REFERENCES}

Abdillahi, H. (1988). Monoclonal antibodies and Neisseria meningitidis. Typing and subtyping for epidemiological surveillance and vaccine development. Netherlands : State University of Utrecht.

Abdillahi, H. \& Poolman, J. T. (1987). Whole-cell ELISA for typing Neisseria meningitidis with monoclonal antibodies. FEMS Microbiol Lett 48, 367-371.

Bjune, G., Closs, O., Frøholm, L. O., Grønnesby, J. K., Høiby, E. A. \& Nøkleby, H. (1991a). Design of clinical trials with an outer membrane vesicle vaccine against systemic serogroup $\mathrm{B}$ meningococcal disease in Norway. NIPH Ann 14, 81-93.

Bjune, G., Høiby, E. A., Grønnesby, J. K., Arnesen, O., Fredriksen, J. H., Halstensen, A., Holten, E., Lindbak, A.-K., Nøkleby, H., Rosenqvist, E., Solberg, L. K., Closs, O., Eng, J., Frøholm, L. O.,
Lystad, A., Bakketeig, L. S. \& Hareide, B. (1991b). Effect of outer membrane vesicle vaccine against group B meningococcal disease in Norway. Lancet 338, 1093-1096.

Butcher, S., Sarvas, M. \& Runeberg-Nyman, K. (1991). Class-3 porin protein of Neisseria meningitidis: cloning and structure of the gene. Gene 105, 125-128.

Chicz, R. M. \& Urban, R. G. (1994). Analysis of MHC-presented peptides: applications in autoimmunity and vaccine development. Immunol Today 15, 155-160.

Chicz, R. M., Urban, R. G., Lane, W. S., Gorga, J. C., Stern, L. J., Vignali, D. A. A. \& Strominger, J. L. (1992). Predominant naturally processed peptides bound to HLA-DR1 are derived from MHCrelated molecules and are heterogeneous in size. Nature 358, 764-768.

Christodoulides, M. \& Heckels, J. E. (1994). Immunization with a multiple antigen peptide containing defined B- and T-cell epitopes: production of bactericidal antibodies against group B Neisseria meningitidis. Microbiology 140, 2951-2960.

Christodoulides, M., McGuinness, B. T. \& Heckels, J. E. (1993). Immunization with synthetic peptides containing epitopes of the class 1 outer-membrane protein of Neisseria meningitidis: production of bactericidal antibodies on immunization with a cyclic peptide. $J$ Gen Microbiol 139, 1729-1738.

de Cossio, M. E. F., Ohlin, M., Llano, M., Selander, B., Cruz, S., del Valle, J. \& Borrebaeck, C. A. K. (1992). Human monoclonal antibodies against an epitope on the class $5 c$ outer membrane protein common to many pathogenic strains of Neisseria meningitidis. $J$ Infect Dis 166, 1322-1328.

Delvig, A., Jahn, S., Kusecek, B., Heckels, J. E., Rosenqvist, E., Høiby, E. A., Michaelsen, T. \& Achtman, M. (1994). A comparison of human and murine monoclonal IgGs specific for the P1.7 PorA protein of Neisseria meningitidis. Mol Immunol 31, 1257-1267.

Feavers, I. M., Suker, J., McKenna, A. J., Heath, A. B. \& Maiden, M. C. J. (1992). Molecular analysis of the serotyping antigens of Neisseria meningitidis. Infect Immun 60, 3620-3629.

Frasch, C. E., Zollinger, W. D. \& Poolman, J. T. (1985). Serotype antigens of Neisseria meningitidis and a proposed scheme for designation of serotypes. Rev Infect Dis 7, 504-510.

Fredriksen, J. H., Rosenqvist, E., Wedege, E., Bryn, K., Bjune, G., Frøholm, L. O., Lindbak, A.-K., Møgster, B., Namork, E., Rye, U., Stabbetorp, G., Winsnes, R., Aase, B. \& Closs, O. (1991). Production, characterization and control of MenB-vaccine 'Folkehelsa': an outer membrane vesicle vaccine against group B meningococcal disease. NIPH Ann 14, 67-79.

Guttormsen, H.-K., Bjerknes, R., Halstensen, A., Næss, A., Høiby, E. A. \& Solberg, C. O. (1993a). Cross-reacting serum opsonins to meningococci after vaccination. J Infect Dis 167, 1314-1319.

Guttormsen, H.-K., Wetzler, L. M. \& Næess, A. (1993b). Humoral immune response to the class 3 outer membrane protein during the course of meningococcal disease. Infect Immun 61, 4734-4742.

Harthug, S., Rosenqvist, E., Høiby, E. A., Gedde-Dahl, T. W. \& Frøholm, L. O. (1986). Antibody response in group B meningococcal disease determined by enzyme-linked immunosorbent assay with serotype 15 outer membrane antigen. J Clin Microbiol 24, 947-953.

Hitchcock, P. J. (1989). Unified nomenclature for pathogenic Neisseria species. Clin Microbiol Rev 2 (Suppl.), S64-S65.

Hobbs, M. M., Seiler, A., Achtman, M. \& Cannon, J. G. (1994). Microevolution within a clonal population of pathogenic bacteria: recombination, gene duplication and horizontal genetic exchange in the opa gene family of Neisseria meningitidis. Mol Microbiol 12, 171-180. 
Holten, E. (1979). Serotypes of Neisseria meningitidis isolated from patients in Norway during the first six months of 1978. J Clin Microbiol 9, 186-188.

Kapperud, G., Nesbakken, T., Aleksic, S. \& Mollaret, H. H. (1990). Comparison of restriction endonuclease analysis and phenotypic typing methods for differentiation of Yersinia enterocolica isolates. J Clin Microbiol 28, 1125-1131.

Laver, W. G., Air, G. M., Webster, R. G. \& Smith-Gill, S. J. (1990). Epitopes on protein antigens : misconceptions and realities. Cell 61, 553-556.

van der Ley, P., Heckels, J. E., Virji, M., Hoogerhout, P. \& Poolman, J. T. (1991). Topology of outer membrane porins in pathogenic Neisseria spp. Infect Immun 59, 2963-2971.

McGuinness, B. T., Barlow, A. K., Clarke, I. N., Farley, J. E., Anilionis, A., Poolman, J. T. \& Heckels, J. E. (1990). Deduced amino acid sequences of class 1 protein (Por $A$ ) from three strains of Neisseria meningitidis. Synthetic peptides define the epitopes responsible for serosubtype specificity. $J$ Exp Med 171, 1871-1882.

McGuinness, B. T., Lambden, P. R. \& Heckels, J. E. (1993). Class 1 outer membrane protein of Neisseria meningitidis: epitope analysis of the antigenic diversity between strains, implications for subtype definition and molecular epidemiology. Mol Microbiol 7, 505-514.

Maiden, M. C. J., Suker, J., McKenna, A. J., Bygraves, J. A. \& Feavers, I. M. (1991). Comparison of the class 1 outer membrane proteins of eight serological reference strains of Neisseria meningitidis. Mol Microbiol 5, 727-736.

Matsushita, S., Takahashi, K., Motoki, M., Komoriya, K., Ikagawa, S. \& Nishimura, Y. (1994). Allele specificity of structural requirements for peptide bound to HLA-DRB1*0405 and -DRB1*0406 complexes: implication for the HLA-associated susceptibility to methimazole-induced insulin autoimmune syndrome. J Exp Med 180, 873-883.

Morelli, G., del Valle, J., Lammel, C. J., Pohlner, J., Müler, K., Blake, M., Brooks, G. F., Meyer, T. F., Koumaré, B., Brieske, N. \& Achtman, M. (1994). Immunogenicity and evolutionary variability of epitopes within IgA1 protease from serogroup A Neisseria meningitidis. Mol Microbiol 11, 175-187.

Mutter, M. \& Vuilleumier, S. (1989). A chemical approach to protein design - template-assembled synthetic proteins (TASP). Angew Chem Int Ed Engl 28, 535-554.

Plikaytis, B. D., Turner, S. H., Gheesling, L. L. \& Carlone, G. M. (1991). Comparisons of standard curve fitting methods to quantitate Neisseria meningitidis group A polysaccharide antibody levels by enzyme-linked immunosorbent assay (ELISA). J Clin Microbiol 29, 1439-1446.

Rosenqvist, E., Høiby, E. A., Wedege, E., Caugant, D. A., Frøholm, L. O., McGuinness, B. T., Brooks, J., Lambden, P. R. \& Heckels, J. E. (1993a). A new variant of serosubtype P1.16 in Neisseria meningitidis from Norway, associated with increased resistance to bactericidal antibodies induced by a serogroup B outer membrane protein vaccine. Microb Pathog 15, 197-205.

Rosenqvist, E., Høiby, E. A., Wedege, E., Kusecek, B. \& Achtman, M. (1993b). The $5 \mathrm{C}$ protein of Neisseria meningitidis is highly immunogenic in humans and stimulates bactericidal antibodies. J Infect Dis 167, 1065-1073.

Saukkonen, K., Abdillahi, H., Poolman, J. T. \& Leinonen, M. (1987). Protective efficacy of monoclonal antibodies to class 1 and class 3 outer membrane proteins of Neisseria meningitidis B:15: P1.16 in infant rat infection model: new prospects for vaccine development. Microb Pathog 3, 261-267.

Spurkland, A., Rønningen, K. S., Leivestad, T., Vartdal, F. \&
Thorsby, E. (1992). HLA-DR-DQ haplotype frequencies in a Norwegian population. Transplant Proc 24, 298-299.

Thompson, S. A., Wang, L. L., West, A. \& Sparling, P. F. (1993). Neisseria meningitidis produces iron-regulated proteins related to the RTX family of exoproteins. J Bacteriol 175, 811-818.

Tinsley, C. R., Virji, M. \& Heckels, J. E. (1992). Antibodies recognizing a variety of different structural motifs on meningococcal Lip antigen fail to demonstrate bactericidal activity. $J$ Gen Microbiol 138, 2321-2328.

Vedros N. A. (1987). Evolution of Meningococcal Disease, vol. 1. Boca Raton, FL: CRC Press.

Vignali, D. A. A. \& Strominger, J. L. (1994). Coreceptor function and the characteristics of MHC-bound peptides. A common link? The Immunologist 2, 112-118.

Virji, M. \& Heckels, J. E. (1989). Location of a blocking epitope on outer-membrane protein III of Neisseria gonorrboeae by synthetic peptide analysis. J Gen Microbiol 135, 1895-1899.

Virji, M., Heckels, J. E., Potts, W. J., Hart, C. A. \& Saunders, J. R. (1989). Identification of epitopes recognized by monoclonal antibodies SM1 and SM2 which react with all pili of Neisseria gonorrboeae but which differentiate between two structural classes of pili expressed by Neisseria meningitidis and the distribution of their encoding sequences in the genomes of Neisseria spp. J Gen Microbiol 135, 3239-3251.

Ward, M. J., Lambden, P. R. \& Heckels, J. E. (1992). Sequence analysis and relationships between meningococcal class 3 serotype proteins and other porins from pathogenic and non-pathogenic Neisseria species. FEMS Microbiol Lett 73, 283-289.

Wedege, E., Bryn, K. \& Frøholm, L. O. (1988). Restoration of antibody binding to blotted meningococcal outer membrane proteins using various detergents. $J$ Immunol Methods 113, 51-59.

Wedege, E., Bjune, G., Frøholm, L. O., Høiby, E. A. \& Rosenqvist, E. (1991). Immunoblotting studies of vaccinee and patient sera from the Norwegian serogroup $\mathrm{B}$ meningococcal vaccination trial. NIPH Ann 14, 183-187.

Wedege, E., Dalseg, R., Caugant, D. A., Poolman, J. T. \& Frøholm, L. O. (1993). Expression of an inaccessible P1.7 subtype epitope on meningococcal class 1 proteins. J Med Microbiol 38, 23-28.

Wiertz, E. J. H. J., Van Gaans-van den Brink, J. A. M., Gausepohl, H., Prochnicka-Chalufour, A., Hoogerhout, P. \& Poolman, J. T. (1992). Identification of $T$ cell epitopes occurring in a meningococcal class 1 outer membrane protein using overlapping peptides assembled with simultaneous multiple peptide synthesis. $J$ Exp Med 176, 79-86.

Wolff, K. \& Stern, A. (1991). The class 3 outer membrane protein (PorB) of Neisseria meningitidis: gene sequence and homology to the gonococcal porin PIA. FEMS Microbiol Lett 83, 179-186.

Zapata, G. A., Vann, W. F., Rubinstein, Y. \& Frasch, C. E. (1992). Identification of variable region differences in Neisseria meningitidis class 3 protein sequences among five group B serotypes. Mol Microbiol 6, 3493-3499.

Zollinger, W. D., Moran, E. E., Connelly, H., Mandrell, R. E. \& Brandt, B. (1984). Monoclonal antibodies to serotype 2 and serotype 15 outer membrane proteins of Neisseria meningitidis and their use in serotyping. Infect Immun 46, 260-266.

Received 30 December 1994; revised 20 March 1995; accepted 22 March 1995. 